\title{
İmmün Plazma Algoritması ile Bilişsel Radyo A ğlarında Çok Kullanıcılı Kanal Atama Probleminin Çözülmesi
}

\author{
Murat Kisa $^{1}$, Selçuk Aslan ${ }^{2}$, Sercan Demirci ${ }^{3 *}$ \\ 1 Ondokuz Mayıs Üniversitesi, Mühendislik Fakültesi, Bilgisayar Mühendisliği Bölümü, Samsun, Türkiye (ORCID: 0000-0003-2054-9677), \\ murat.kisa@bil.omu.edu.tr \\ ${ }^{2}$ Erciyes Üniversitesi, Havacılık ve Uzay Bilimleri Fakültesi, Uçak Mühendisliği Bölümü, Kayseri, Türkiye (ORCID: 0000-0002-9145-239X), \\ selcukaslan@erciyes.edu.tr \\ 3* Ondokuz Mayıs Üniversitesi, Mühendislik Fakültesi, Bilgisayar Mühendisliği Bölümü, Samsun, Türkiye (ORCID: 0000-0001-6739-7653), \\ sercan.demirci@bil.omu.edu.tr
}

(International Symposium on Multidisciplinary Studies and Innovative Technologies (ISMSIT) 2021 -21-23 October 2021)

(DOI: $10.31590 /$ ejosat.1024761)

ATIF/REFERENCE: Kısa, M., Aslan, S. \& Demirci, S. (2021). İmmün Plazma Algoritması ile Bilişsel Radyo Ağlarında Çok Kullanıcılı Kanal Atama Probleminin Çözülmesi. Avrupa Bilim ve Teknoloji Dergisi, (29), 304-310.

$\ddot{\mathbf{O} z}$

Aralık 2019'da Çin'de başlayan ve tüm dünyayı etkisi altına alan koronavirüs (COVID-19) pandemisi olarak bilinen sağlık krizi, her ne kadar Tıbbi alanlarla doğrudan alakalı olsa da mevcut teşhis ve tedavi yöntemleri üzerine yapılan çalışmalar, bilgisayar bilimlerinden araştırmacıların da bu tedavi yöntemlerinden esinlenerek çalışmalar yapmasııı mümkün kılmıştır. Bu çalışmada immün plazma tedavisinin temel işlem adımlarını dayanak noktası alan İmmün Plazma algoritması, bilişsel radyo ağlarında aynı zaman diliminde birden fazla bilişsel radyo kullanıcısının yayın yaptığı kanal atama probleminin özellikleri dikkate alınarak modifiye edilmiş ve bilişsel radyo kullanıcılarının aynı zaman dilimi içerisinde farklı kanalları kullanmalarını sağlamak amacıyla bir yöntem geliştirilerek bahsedilen problemin çözümündeki performansı incelenmiştir. Ayrıca, önerilen IPA temelli yöntem ile elde edilen sonuçlar Kaba Kuvvet arama ile elde edilen sonuçlar kullanılarak karşılaştırılmıştır. Karşılaştırma sonuçları IP algoritmasının bahsedilen arama yöntemine kıyasla daha başarılı sonuçları elde edebileceğini göstermiştir.

\section{Solving Multiuser Channel Assignment Problem in Cognitive Radio Networks with Immune Plasma Algorithm}

\begin{abstract}
The health crisis, known as the coronavirus (COVID-19) pandemic, which started in China in December 2019 and affected the whole world, although it is directly related to the medical fields, studies on current diagnosis and treatment methods suggest that researchers from computer sciences can also use this treatment enabled him to work inspired by his methods In this study, the Immune Plasma algorithm, which is based on the basic process steps of immune plasma therapy, has been modified by considering the characteristics of the channel assignment problem in which more than one cognitive radio user broadcasts in the same time slot. A method is used to enable cognitive radio users to use different channels in the same time period developed and its performance in solving the mentioned problem was examined. In addition, the results obtained with the proposed IPA-based method are compared using the results obtained by Brute Force search. The comparison results showed that the IP algorithm can achieve more successful results compared to the mentioned search method.
\end{abstract}

Keywords: Meta-heuristics, Immune Plasma algorithm, channel assignment.

*Sorumlu Yazar: sercan.demirci@bil.omu.edu.tr 


\section{Giriş}

Kablosuz ağlarda kısıtlı kaynakları verimli bir şekilde kullanmak oldukça zor bir iştir. Sınırlı kaynaklardan daha verimli bir şekilde faydalanmak için bilişsel radyolar önerilmiştir [1, 4, 5]. Bilişsel Radyo (CR), lisanssız spektrum ya da frekanstaki yetersizliği azaltmak ve verimliliği arttırmak için umut verici bir teknoloji olarak görülmüştür $[6,8]$. Bilişsel radyo ağları, fırsatçı iletim ve dinamik frekans erişimi gibi yetenekleri sayesinde radyo frekanslarının etkin bir şekilde kullanılmasını sağlar [7]. Bilişsel radyo ağları, ağ üzerinde doğrudan yayın yapma hakkına sahip lisanslı (birincil) ve ağ üzerinde lisanslı kullanıcıların yayın yapmadığı zamanlarda yayın yapma talebinde bulunan lisanssiz (ikincil) kullanıcılar bir arada bulunur. Bilişsel radyolar dış dünyayı algılama, öğrenme ve ona uyum sağlama becerisine sahiptir. $\mathrm{Bu}$ yetenekleriyle lisanslı kullanıcıların yaptığı yayını olumsuz etkilemeden, kullanılmayan frekans kaynaklarını lisanssız kullanıcıların kullanımına açabilmektedir [5].

Bilişsel radyo ağlarında kanal atamasının hızlı ve doğru bir biçimde gerçekleştirilmesi için evrimsel yöntemler, lineer programlama ve meta-sezgisel algoritmaların da bulunduğu farklı yöntemler kullanılmıştır. Dokuz çalışmasında, kanal atama probleminin çözümü için Yapay Arı Koloni algoritması temelli bir model sunmuştur ve bu yeni modelle elde ettiği skorları Karınca Koloni algoritması ile karşılaştırmıştır [11]. Her iki algoritmayla da elde edilen skorlar incelendiğinde Yapay Ar1 Koloni algoritması daha iyi sonuçlar vermiştir [11]. Salameh çalışmasında tek alıcı-vericideki frekans erişim problemine odaklanarak frekans ataması ve iletim hızını en üst düzeye çıkartmak istemiştir. Geliştirilen protokolle ağın verimi adaletli bir şekilde iyileştirilmiştir [5]. Qin ve ark. bilişsel radyo ağlarında kanal atama ve firsatçı yönlendirmenin birlikte uygulandığ 1 yeni bir problem üzerinde durmuşlardır ve çalışmalarında ele aldıkları problemi bir sezgisel yaklaşım kullanarak çözümlendirmişlerdir. [12]. Bu önerdikleri yeni sezgisel yöntemin literatürdeki diğer yönlendirme ve atama yöntemlerine kıyasla daha başarılı olduğunu göstermişlerdir. [12]. Wei ve Hu ağ üzerindeki lisanssız kullanıcılar için çok kanallı seçim yeteneğini kullanarak en yüksek adalet seviyesine sahip kanal ataması yapmayı hedeflemişlerdir [13]. Önerdikleri yeni yaklaşımın diğer spektrum atama yöntemleri ile kıyasladıklarında daha başarılı sonuçlar elde etmişlerdir [13]. Demirci ve Gözüpek bilişsel ağlarda kanal değiştirilmesiyle ortaya çıkan enerji tüketimi probleminin çözümü için sezgisel bir yöntem olan polinom zamanlı algoritma önermişlerdir [14]. Endüstriyel bilişsel radyo ağlarında frekans ataması yapılırken frekans değişikliği gerçekleştiğinde ortaya çıkan enerji maliyetinin en aza indirgenmesi için frekans atama ve çizelgeleme problemini modellemişlerdir [14]. Salameh ve ark. bilişsel radyo ağları için farklı ağ koşulları ve farklı trafik etkenlerinin kanal atamasını nasıl etkilediğini test etmek için yeni bir kanal ataması yöntemi ve uyarlanabilir protokol önermişlerdir [15]. Raju ve ark. Çekirge algoritmasını kullanarak kanal atama probleminin çözümünü gerçekleştirmişlerdir [16]. Musa ve ark. çalışmalarında yeni bir güç kontrollü kanal atama prokolü geliştirmek için fiziksel girişim modelinden faydalanmışlardır. Önerilen yeni atama protokolüyle, spektrum kullanımını ve ağ verimini literatürde yapılan diğer çalışmalarda kullanılan protokollere kıyasla daha iyi olduğunu göstermişlerdir [17]. Latif ve ark. bilişsel ağda ikincil kullanıcılar için spektrum atamasını daha verimli hale getirmek için Parçacık Sürü
Optimizasyonu algoritmasından faydalanmışlardır. Önerdikleri bu yeni yöntem ile ikincil kullanıcılar arasındaki etkileşimi azaltmayı başarmışlardır [18]. Sanka ve ark. kanal atama probleminin çözümü için meta sezgisel bir yöntem olan Dragonfly algoritmasını kullanmışlardır. [19]. Tlouyamma ve Velempini çalışmalarında bilişsel ağın, lisanslı olmayan kulanıcıların yayın yapacağı kanallara karar verirken lisanslı kullanıcıların olası yayınlarını değerlendirmişlerdir. $\mathrm{Bu}$ geliştirdikleri yaklaşım ile gecikmeleri büyük ölçüde azaltabilmişlerdir. [20]. Devi var Ark. çalışmalarında kullanılmayan kanalları verimli şekilde paylaştırmak ve yeniden kullanım özelliğini genişleten bir açık arttırma yöntemi sunmuşlardır. Bu yöntemde müzayedeci bir teknik kullanarak, lisanssız kullanıcılardan toplanan tekliflere göre kazananı belirleyip kullanılmayan kanalların etkin bir şekilde kullanılması sağlanmıştır [22]. Yılmazel ve Ark. yapay zeka teknikleri ve frekans atama algoritmalarını birleştirerek yeni bir yaklaşım önermişlerdir [23]. En iyi ve en yüksek kanal tahsisini yapmak için Genetik algoritma kullanılmıştır ve genetik algoritma kullanılmadan yapılan çalışmalara göre daha iyi sonuçlar elde edilmiştir [23]. Goyal ve ark. A ̆g üzerinde iletim sırasında oluşabilecek çakışmaları önlemek ve kanalların verimli kullanılmasını sağlamak için dağıtılmış bir kanal atama algoritması önermişlerdir. $\mathrm{Bu}$ yöntemle paketlerin hedeflerine iletilme oranını ve kanal kullanımını önemli ölçüde arttırmışlardır [24]. Agarwal ve ark. çalışmalarında lisanslı kullanıcıların kullandıkları kanalları tahmin etmek ve algılamak için geliştirilmiş Yapay Arı Koloni (ABC) algoritması önermişlerdir. Önerilen bu geliştirilmiş yöntem sayesinde lisanssız kullanıcılar için frekans tahsisi daha doğru yapılarak ağın verimliliği arttırılmıştır [25].

$\mathrm{Bu}$ çalışmada, bilişsel radyo ağlarında birden fazla lisanssız kullanıcının bulunduğu kanal atama probleminin çözümü için yeni bir meta-sezgisel yöntem olan İmmün Plazma algoritmasından (IP algoritması) [21] faydalanılarak yeni bir yöntem önerilmiştir. IP algoritması birden fazla lisanssız kullanınıcının bulunduğu kanal atama probleminin özellikleri dikkate alınarak güncellenmiştir. Lisanslı olmayan kullanıcılara atanan kanalların değişimine bağlı olarak ortaya çıkan maliyetin en aza indirgenmesi hedeflenmiştir. Çalışmanın ikinci bölümünde kanal atama problemi ve kanal atama maaliyetinin minimizasyonunu dikkate alan model açıklanmıştır ve bilişsel radyo ağı üzerinde oluşabilecek frekans çakışmalarının önüne geçmek için oluşturulan düzenleme fonksiyon modelinden bahsedilmiştir. Üçünücü bölümde IP algoritmasının işlem adımları için kullanılan matematiksel modeller detaylandırılmış, IP algoritmasının birden fazla lisanssız kullanıcının bulunduğu kanal atama problemi için nasıl düzenlendiği açıklanmıştır. Dördüncü bölümde sunulan bu yeni yöntemin, farklı senaryolarla elde edilen sonuçları ve detayları değerlendirilmiştir. Son bölümde ise sonuçlara yer verilmiştir.

\section{Kanal Atama Problemi}

Bilişsel radyo ağları, lisanslı (birincil) ve lisanssız (ikincil) kullanıcıların bir arada bulunmasına izin vermektedir. Lisanslı kullanıcılar yayın yapma hakkında doğrudan sahiptir. Lisansız kullanıcılar ise belirli kurallar çerçevesinde lisanslı kullanıcıların yayın yapmadığı zamanlarda yayın yapabilmektedir. Böylelikle bilişsel radyo ağlarında firsatçı iletim ve dinamik frekans erişim yetenekleri ile radyo frekanslarının verimli bir şekilde kullanılması sağlanmaktadır. Lisanslı olmayan kullanıcıların yayın taleplerine boşta olan frekanslar arasından dinamik frekans 
seçimi yapılarak cevap verilebilir [9]. Bilişsel radyonun asıl amacı bilişsel yetenekleri kullanılarak en iyi kanalı elde edebilmektir.

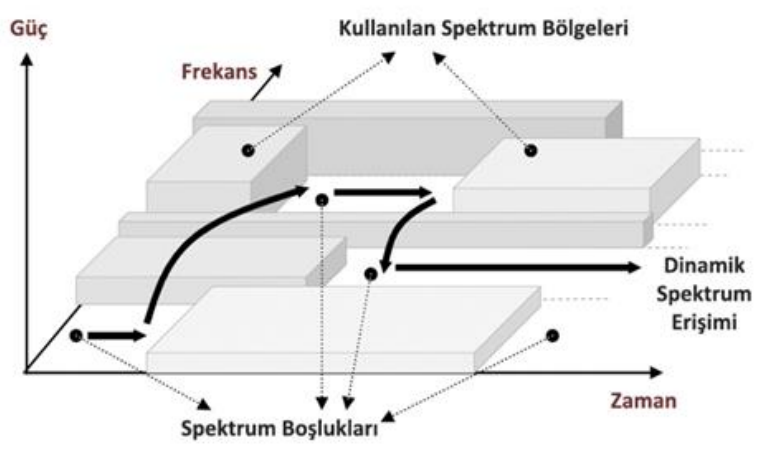

Şekil 1. Spektrum Boşluk Yapısı [3].

Şekil 1'de görüldüğü gibi lisanslı spektrum diğer lisanslı kullanıcıların yayın yapmasını etkilemeyecek şekilde paylaştırılmaktadır. Bilişsel radyo spektrum boşluğu veya beyaz boşluk olarak adlandırılan ve geçici olarak kullanılmayan spektrumun kullanılmasına olanak sağlamaktadır. Eğer frekans lisanslı bir kullanıcı tarafindan kullanılıyorsa bilişsel radyo kullanıcısı müsait olan başka bir frekansa geçer ya da girişime sebep vermeyecek şekilde iletim gücü değiştirilerek aynı frekans üzerinden yayın yapmaya devam eder. Bilişsel radyo ağı için lisanslı kullanıcıların iletişimini korumanın önemli olması nedeniyle spektrum sezme, spektrum yönetimi, spektrum değiştirme ve spektrum paylaşma gibi dört temel özelliğe sahip olmalıdır [6].

- Spektrum sezme: Atıl durumdaki spekturumun tespit edilmesi ve bu spektrumun diğer kullanıcıların yaptığı yayını etkilemeden paylaşılmasıdır.

- Spektrum yönetimi: Kullanıcıların yayın gereksinimlerine en uygun spektrumun belirlenmesidir.

- Sprektrum değiştirme: Sorunsuz bir iletişim gerçekleştirebilmek için gerektiğinde kullanılan spektrumun değiştirilmesidir.

- Spektrum paylaşma: Ağ üzerinde bir arada bulunan lisanssız kullanıcılar arasında adaletli bir spektrum paylaşımı gerçekleştirilmesidir.

Bilişsel radyo ağları, çalışma parametrelerini etkin bir şekilde değiştirerek spektrumları görürler, boşta bulunan bantları sezerler ve müsait durumda olan bantları lisanssız kullanarak genel spektrum kullanımını arttırırlar. Lisanslı bantlarda, lisansa sahip olan kablosuz kullanıcıların tahsis edilen bant üzerinden yayın yapabilmesine ve kanala erişim sağlamasına izin verilmektedir. Birincil kullanıcılar yayın yapmaya başladığı zaman, bilişsel radyo kullanıcısı müsait durumda olan frekansları belirler ve daha sonra bu müsait frekanslar arasından seçim yapar, alıcısını ve vericisini ayarlayarak yeni frekans üzerinden yayın yapmaya başlar [10].

Birden fazla bilișsel radyo kullanıcısın bulunduğu kanal atama probleminde temel amaç bilişsel ağdaki frekans kullanımını en üst düzeye çıkarmaktır. Fakat ağdaki kullanıcıların yayın yaptıkları frekansları doğrudan veya dolaylı olarak değiştirmesi, güç ayarlarının tekrardan uygunlanmasını gerektirdiğinden yeni frekansa geçiş esnasında kısa süreli gecikmeler oluşabilmektedir. Burada dikkat edilmesi gereken bir diğer konu da lisanslı kullanıcıların kullanmadığı frekansların bilişsel radyo kullanıcıları tarafından da aynı zaman diliminde kullanılmaması gerektiğidir. Problem çözülürken lisanslı olmayan herhangi bir $k$ kullanıcısı için yapılan atamaların uygunluğunu göstermek amacıyla Eşitlik 1 ile hesaplanan skordan faydalanılmıştır [11].

$$
C_{k}=\sum_{i=1}^{C R} \sum_{j=1}^{N-1} f_{k}[i][j]
$$

Eşitlik 1'de verildiği üzere $C R$ bilişsel radyo kullanıcılarının sayısını temsil etmektedir. $N$ parametresi yayın yapılabilen dakikalara karşılık gelmektedir. $f_{k}[i][j]$ değeri $i$ 'inci bilişsel radyo kullanınıcısı için frekans değişilikliği olup olmaması dikkate alınarak belirlenmektedir. Eğer $j$ 'inci dakikadan $j+1$ 'inci dakikaya geçerken frekans değişikliği tespit edilirse değeri bir, değișiklik yoksa sıfır olarak atanır. Hesaplanılan skor ile her bir bilişisel radyo kullanıcısı için $N$ dakikalık zaman diliminde yaptığı yayın dikkate alınarak en uygun şekilde yapılan atamaların $C_{k}$ değerini minimum yaptığı görülmektedir.

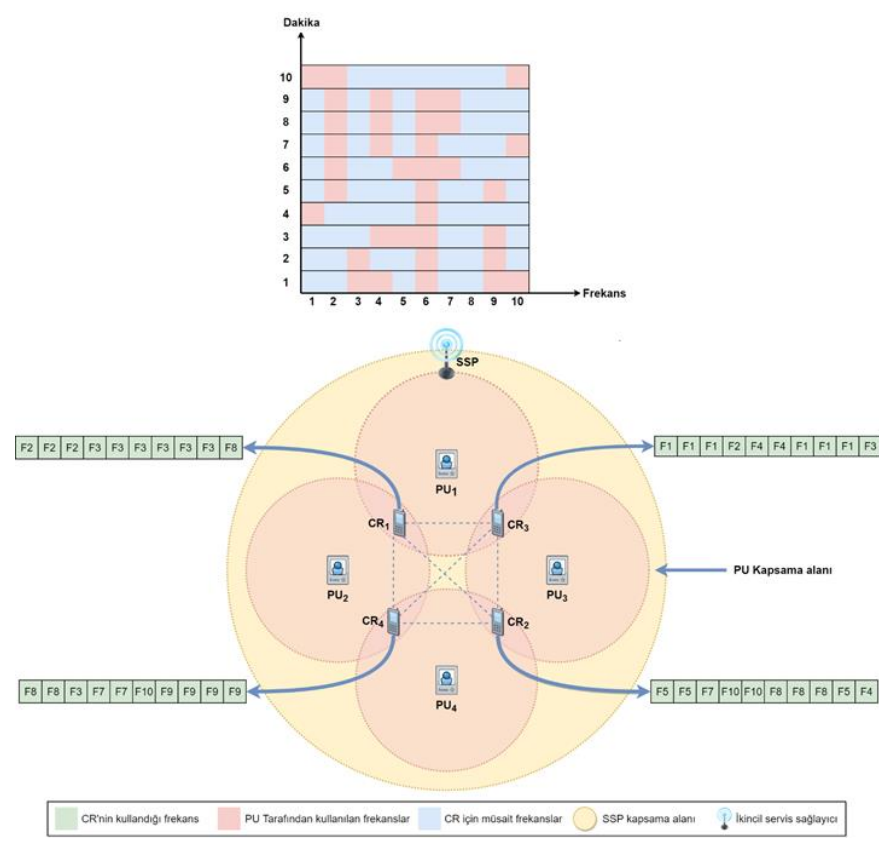

Şekil 2. Tasarlanan bilişsel radyo ăg modeli [14]. 
Tablo 1. Çalışmada Kullanılan Veri Seti

\begin{tabular}{|c|c|c|c|c|c|c|c|c|c|c|}
\hline$D_{k}^{F}$ & 1 & 2 & 3 & 4 & 5 & 6 & 7 & 8 & 9 & 10 \\
\hline 1 & 0 & 0 & 1 & 1 & 0 & 1 & 0 & 0 & 1 & 1 \\
\hline 2 & 0 & 0 & 1 & 0 & 0 & 1 & 0 & 0 & 1 & 0 \\
\hline 3 & 0 & 0 & 0 & 1 & 1 & 1 & 0 & 0 & 1 & 0 \\
\hline 4 & 1 & 0 & 0 & 0 & 0 & 1 & 0 & 0 & 0 & 0 \\
\hline 5 & 0 & 1 & 0 & 0 & 0 & 1 & 0 & 0 & 1 & 0 \\
\hline 6 & 0 & 1 & 0 & 0 & 1 & 1 & 1 & 0 & 0 & 0 \\
\hline 7 & 0 & 1 & 0 & 1 & 0 & 1 & 0 & 0 & 0 & 1 \\
\hline 8 & 0 & 1 & 0 & 1 & 0 & 1 & 1 & 0 & 0 & 0 \\
\hline 9 & 0 & 1 & 0 & 1 & 0 & 1 & 1 & 0 & 0 & 0 \\
\hline 10 & 1 & 1 & 0 & 0 & 0 & 0 & 0 & 0 & 0 & 1 \\
\hline 11 & 1 & 1 & 0 & 0 & 0 & 0 & 0 & 0 & 0 & 1 \\
\hline 12 & 1 & 1 & 0 & 0 & 0 & 0 & 0 & 0 & 0 & 1 \\
\hline 13 & 0 & 0 & 0 & 0 & 0 & 0 & 0 & 0 & 0 & 1 \\
\hline 14 & 0 & 0 & 0 & 1 & 1 & 0 & 0 & 0 & 0 & 0 \\
\hline 15 & 0 & 0 & 0 & 0 & 1 & 1 & 1 & 1 & 1 & 0 \\
\hline 16 & 0 & 0 & 0 & 0 & 1 & 1 & 1 & 1 & 0 & 1 \\
\hline 17 & 0 & 1 & 0 & 1 & 0 & 1 & 1 & 1 & 0 & 0 \\
\hline 18 & 0 & 1 & 0 & 1 & 1 & 1 & 1 & 1 & 0 & 0 \\
\hline 19 & 0 & 1 & 0 & 1 & 1 & 1 & 0 & 1 & 0 & 1 \\
\hline 20 & 1 & 1 & 0 & 0 & 0 & 1 & 0 & 0 & 0 & 0 \\
\hline
\end{tabular}

Bilişsel radyo kullanıcılarının aynı zaman diliminde aynı frekansı kullanarak yayın yapmaya çalışması ihtimali kanal atama problemini daha da karmaşık hale getirmektedir. Bilişsel radyo kullanıcıları aynı zaman diliminde farklı frekansları kullanmalıdır. Aynı frekans üzerinden yayın yapmaya çalışırlarsa çakışmalar meydana gelebilir ve iki kullanıcı da yayın yapamaz hale gelir. Bu durumu ortadan kaldırmak için bir düzenleme fonksiyonu önerilmiştir. $\mathrm{Bu}$ fonksiyon modifiye edilmiş IP algoritmasına yardımcı olarak, ă̆ üzerinde ortaya çıkan çakışmaları kontrol edip varsa düzenleyerek işlem yapmaktadır. İşlem adımları Algoritma 1 üzerinde gösterilmiştir.

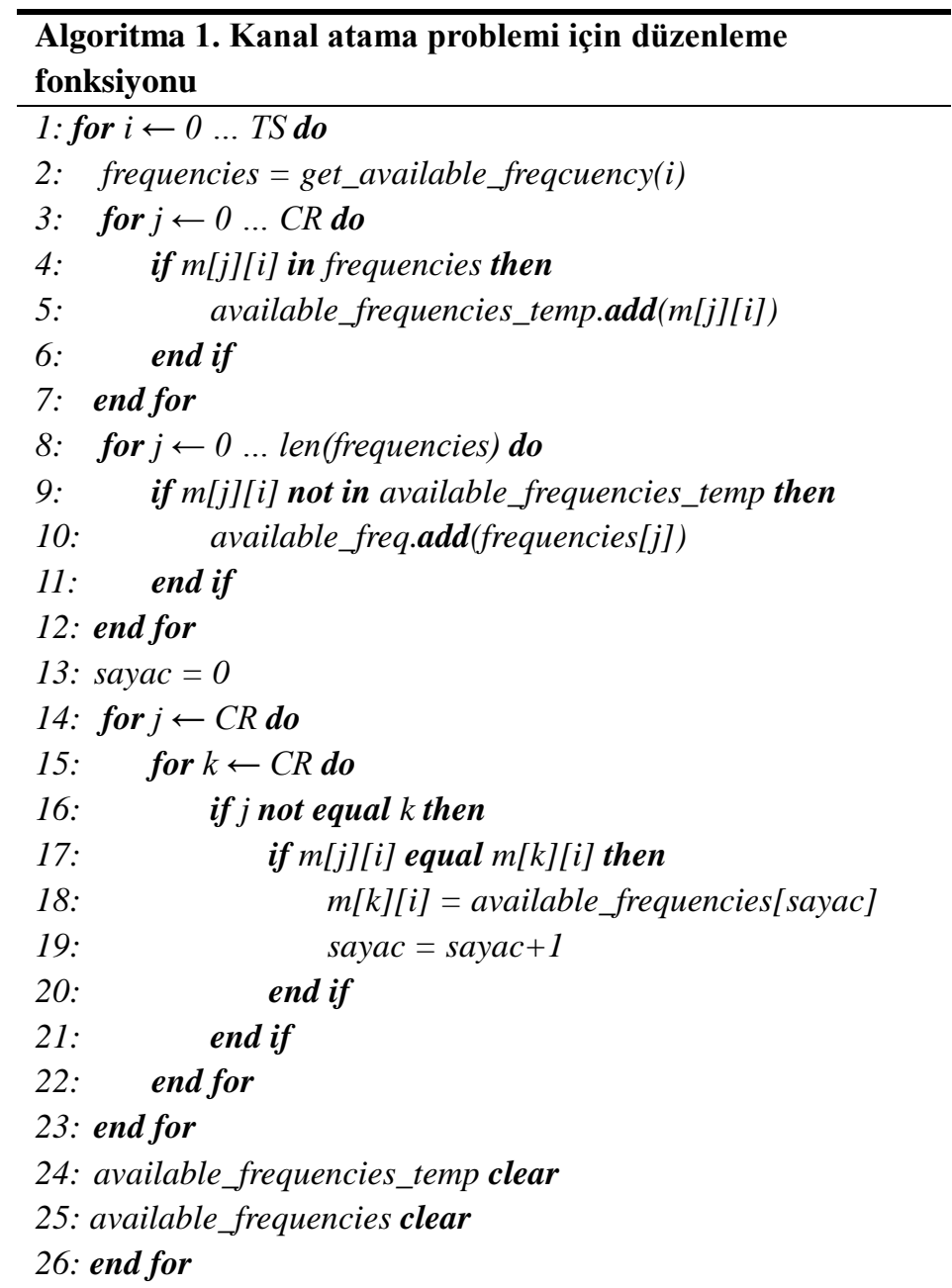

Algoritma 1 ile açıklanan düzenleme fonksiyonunda ilk olarak i’inci zaman dilimindeki müsait frekanslar bir diziye atanmıştır. Oluşturulan bu müsait frekans dizisi içindeki frekanslar bilişsel radyo kullanıcıları tarafından kullanılıyorsa bu frekanslar geçici bir diziye alınarak müsait frekans dizisinden çıkarılması sağlanmıştır ve gerçek müsait frekanslar dizisi oluşturulmuştur. Elde edilen bu diziyle bilişsel radyo kullanıcılarının i'inci zaman diliminde hangi frekansı kullandığını araştırılmıştır. Eğer farklı bilişsel radyo kullanıcılarının aynı frekansı kullandığı tespit edilirse bilişsel radyo kullancılarından birinin kullandığı frekans gerçek müsait frekans dizisinden sıraya göre seçilerek bilişsel radyo kullanıcıları arasında oluşan frekans çakışması ortadan kaldırılmıştır.

\section{3. İmmün Plazma Algoritması}

Bağışıklık sistemi, vücudu enfeksiyonlara ve diğer hastalıklara karşı koruyan, komplike ve çok katmanlı bir sistemdir. Bağışıklık sisteminde vücudun yaşam döngüsü boyunca karşılaştığı tüm mikropların kaydı tutulmaktadır. Daha önce karşılaşılmış mikroplarla tekrar karşılaşılması durumunda, bunları algılayarak vücudu enfeksiyonlara karşı korumaktadır. Bağ ${ }_{1}{ }_{1}$ klık sistemi enfeksiyona karşı koymak için, enfeksiyonun kaynağı olan bileşenlere bağlanarak diğer sağlıklı hücreleri etkilemelerine engel olan antikorların $B$ ve $T$ hücrelerini kullanarak sentezlenmesini sağlar. Fakat enfeksiyon oranın 
yüksek olması veya bağışıklık sisteminin zayıf olması gibi durumlarda antikor sentezi yetersiz kalabilir. Böyle durumlarda enfeksiyonu kısa süre önce atlamış olan bireylerdeki kanın antikor yoğun ve plazma olarak adlandırılan kısmı kritik bireylere nakledilerek kullanılabilir. $\mathrm{Bu}$ yöntemin adı immün plazma tedavisidir.

Yeni bir meta-sezgisel yöntem olan İmmün plazma algoritması bu bahsedilen immün plazma tedavisinin temel işlem adımlarını ve uygulama prensiplerini dayanak noktası olarak almaktadır.

\subsection{Popülasyonun Oluşturulması}

Popülasyon büyüklüğü PS olan algoritma D parametreli bir problem için $x_{k}$ bireyinin j'inci parametresinin değeri Eşitlik (2) kullanılarak oluşturulur. $x_{j}^{\max }$ ve $x_{j}^{\min }$ bireyin j'inci parametresinin alt ve üst limitlerini temsil etmektedir. $\operatorname{rand}(0,1)$ sıfır ile bir arasında üretilen rastgele bir sayıdır [21]. Kanal atama probleminin çözümü için oluşturulan değer eğer bir tam sayı değilse en yakın tam sayıya yuvarlanıp, müsaitlik kontrolü yapılmıştır.

$$
x_{k j}=x_{j}^{\min }+\operatorname{rand}(0,1)\left(x_{j}^{\max }-x_{j}^{\min }\right)
$$

\subsection{Enfeksiyonun Yayılması ve Bağışıklık Cevabı}

Enfeksiyonun yayılması için IP algoritması Eşitlik (3)'ü kullanmaktadır. Eşitlik (3) üzerinde $x_{k j}^{\text {inf }}$ enfekte olan $x_{k j}$ bireyinin rasgele belirlenmiş j'inci parametresinin değeridir. rand $(-1,1)$ değeri -1 ile 1 arasında rastgele belirlenmiş bir sayıdır. $x_{m}$ bireyi $x_{k}$ bireyinden farklı olmak şartıyla popülasyondan rasgele şeçilmiş bir bireyin j'inci parametresidir. Kanal atama probleminin çözümü için enfekte edimiş bireyin değeri en yakın tam sayıya yuvarlanarak müsaitlik kontrolü yapılmıştır. Eğer enfeksiyon sonrası yuvarlanmış değer müsaitlik kontrolü sonrası değeri enfeksiyon öncesi değerinden farklıysa ve elde edilen skor ile temsil edilen frekans müsait değilse, yeni skorun karşılık geldiği frekansı kullanan bireyin değeri $x_{k}$ bireyinin enfeksiyon öncesi değeri ile değiştirilir.

$$
x_{k j}^{i n f}=x_{k j}+\operatorname{rand}(-1,1)\left(x_{k j}-x_{m j}\right)
$$

Bireylerin bağışıklık öncesi değeri $f\left(x_{k j}\right)$ ile bağışıklık sonrası değeri ise $f\left(x_{k j}^{i n f}\right)$ ile tanımlanmaktadır [21]. Eğer $f\left(x_{k j}^{i n f}\right)$ değeri $f\left(x_{k j}\right)$ değerinden daha küçükse $x_{k j}$ parametresinin değeri $x_{k}^{\text {inf }}$ ile Eşitlik (4)’te gösterildiği üzere güncellenir. Diğer durumda ise $x_{k j}$ parametresi değiştirilmeden bırakılır.

$$
x_{k j}=\left\{\begin{array}{ll}
x_{k j}^{i n f} ; & \text { if } f\left(x_{k}^{i n f}\right)<f\left(x_{k}\right) \\
x_{k j} ; & \text { if } f\left(x_{k}^{\text {inf }}\right) \geq f\left(x_{k}\right)
\end{array}\right\}
$$

\subsection{Plazma Transferi}

Enfeksiyon popülasyondaki tüm bireyler arasında yayıldıktan sonra IPA donör ve alıcı olacak olan bireyleri belirler. Donör birey bağışıklık seviyesi en iyi olan NoD birey, alıcı birey ise bağışıklık seviyesi en kötü olan birey ise NOR birey olarak atanır. $\quad x_{k}^{r c v}$ alıcı bireyi ve donör bireyler arasından rastgele seçilen $x_{m}^{d n r}$ donör bireyine ait plazma transferi Eşitlik (5) ile yapılmaktadır. $x_{k j}^{r c v-p}$ değeri $x_{k}^{r c v}$ bireyinin plazma transferi sonrası $(1,2, \ldots, D)$ kümesinden sırasıyla seçilen j'inci parametresinin yeni değeridir ve problemin çözümü için elde edilen değer en yakın tam sayıya yuvarlanmıştır ve müsaitlik kontrolü yapılmıştır.

$$
x_{k j}^{r c v-p}=x_{k j}^{r c v}+\operatorname{rand}(-1,1)\left(x_{k j}^{r c v}-x_{m j}^{d n r}\right)
$$

Eğer $x_{k j}^{r c v}$ alıcı bireyinin plazma tedavisi sonrası bağışıklık cevab1 $x_{k j}^{r c v-p}$ değeri ile gösterilmiştir. Ĕ̆er $f\left(x_{k j}^{r c v-p}\right)$ değeri $f x_{k j}^{r c v}$ değerinde daha küçük ise birey bağışıklık sonrası değeri ile güncellenir ve ikinci doz plazma hazırlanır [21]. Diğer durumda $x_{k}^{r c v}$ bireyi ile $x_{m}^{d n r}$ bireyi ile değiştirilerek tez doz plazma transferi gerçekleştirilir.

Tedaviye yanıt vermeyen ve kritik seyir gösteren bireylerin tedavisine plazma donörü olarak katkı sunan bireylerin bağışıklık cevabı zamana göre değişebilir. IP algoritması donör bireylerin bağışıklık cevabının değişimi ilgili değerlendirme sayısını $\left(t_{c}\right)$ ve maksimum değerlendirme sayısı $\left(t_{\max }\right)$ değerlerine bağlı olarak modellenir [21]. $x_{m j}^{d n r}$ donör bireyi için $t_{c} / t_{\max }$ oranı, değeri 0 ile 1 arasında rasgele seçilen sayıdan küçük ise $x_{m j}^{d n r}$ donör birey Eşitlik (2) kullanılarak yeniden oluşturulur. Eğer büyükse Eşitlik (6) kullanılarak sınırlı olarak değiştirilir. Eşitlik (6) ile değiştirilen birey kanal atama problemi çözümü için mutlaka en yakın tam sayıya yuvarlanıp ve müsaitlik kontrolü yapılmalıdır.

$$
x_{m j}^{d n r}=x_{m j}^{d n r}+\operatorname{rand}(-1,1) x_{m j}^{d n r}
$$

\section{Araştırma Sonuçları ve Tartışma}

Dört farklı bilişsel radyo kullanıcısının aynı zaman diliminde yayın yaptıkları kanal atama probleminin çözümü için modifiye edilen IP algoritmasının başarısı Tablo 2'de verilen senaryo üzerinden incelenmiştir. Algoritmanın popülasyon büyüklüğü için 30,50 ve 100 değerleri belirlenmiştir. IP algoritması için donör ve alıcı birey sayısına bağlı olarak oluşan etkinin analizi amaciyla NoR ve NoD parametrelerinin değerleri 1 ve 2 olarak alınmıştır. Popülasyon büyüklügüu, NoR ve NoD parametrelerine atanan farklı değerler ile dört adet bilişsel radyo kullanılarak, IPA maksimum değerlendirme sayısı 15000 alınarak 30 farklı sefer çalıştırılarak test edilmiştir. Her test ya da değerlendirme sonucu IPA tarafindan elde edilen en iyi çözüm ve bu çözüme ait amaç fonksiyon skorları hafızada tutularak 30 farklı değerlendirme ile elde edilen en iyi skorların amaç fonksiyon değerlerinin ortalaması, standart sapması hesaplanmış ve Tablo 2'de verilmiştir. 
fonksiyon dĕgerleri ve standart sapmalart

\begin{tabular}{|c|c|c|c|c|}
\hline \multirow{3}{*}{ Sen. } & \multicolumn{4}{|c|}{$P S=30$} \\
\hline & \multicolumn{2}{|c|}{$N o R=1$} & \multicolumn{2}{|c|}{$N o R=2$} \\
\hline & $N o D=1$ & $N o D=2$ & $N o D=1$ & $N o D=2$ \\
\hline Ort. & 36.4664 & 41.7333 & 42.6 & 37.0333 \\
\hline Std. & 1.6069 & 2.0483 & 3.0832 & 1.3287 \\
\hline \multirow{3}{*}{ Sen. } & \multicolumn{4}{|c|}{$P S=50$} \\
\hline & \multicolumn{2}{|c|}{$N o R=1$} & \multicolumn{2}{|c|}{ NoR $=2$} \\
\hline & $N o D=1$ & $N o D=2$ & $N o D=1$ & $N o D=2$ \\
\hline Ort. & 39.9333 & 46.2333 & 42.6333 & 40.2666 \\
\hline Std. & 1.3399 & 2.7529 & 2.8923 & 1.5691 \\
\hline \multirow{3}{*}{ Sen. } & \multicolumn{4}{|c|}{$P S=100$} \\
\hline & \multicolumn{2}{|c|}{$N o R=1$} & \multicolumn{2}{|c|}{$N o R=2$} \\
\hline & $N o D=1$ & $N o D=2$ & $N o D=1$ & $N o D=2$ \\
\hline Ort. & 44.1333 & 50.1666 & 40.4333 & 43.9 \\
\hline$S t$ & 1.5216 & 2.1304 & 2.5124 & 1.88 \\
\hline
\end{tabular}

Tablo 2'deki sonuçlar incelendiğinde popülasyon boyutunun 30 , NoD ve NoR parametrelerinin 1 olarak belirlendiği durumda en iyi sonucu verdiği görülmektedir. Tablo 2'ye göre popülasyon sayısı yüksek ve çözüm çeşitliliğinin fazla seçildiği duruma göre popülasyon sayısının daha küçük seçilmesinin daha uygun olduğu görülmektedir. NoR ve NoD parametrelerinin seçimleri de Tablo 2'deki sonuçlara bakıldığında IP algoritmasının çalışma performansını etkilemektedir. NoR ve NoD sayısı eşit seçildiğinde popülasyondaki birey sayısının 30 ve 50 , NoD sayısı NoR sayısından daha küçük seçildiğinde ise birey sayısının 100 olduğu senaryolarda daha iyi sonuç vermektedir.

Tablo 3 üzerinde algoritmanın 30 farklı kez çalışmasına ait ortalama tamamlanma süreleri ve standart sapmaları gösterilmiştir. Tablo 3 üzerindeki sonuçlara göre popülasyondaki birey sayısı 30 seçildiğinde NoR ve NoD sayısı ve plazma transferinin daha fazla gerçekleşmesinden dolayı tamamlanma sürelerinin arttığı gözlemlenmektedir.

Tablo 3. IPA için bulunan ortalama tamamlanma süreleri ve standart sapmalart

\begin{tabular}{|c|c|c|c|c|}
\hline \multirow{3}{*}{ Sen. } & \multicolumn{4}{|c|}{$P S=30$} \\
\hline & \multicolumn{2}{|c|}{$N o R=1$} & \multicolumn{2}{|c|}{$N o R=2$} \\
\hline & NoD $=1$ & $N o D=2$ & $N o D=1$ & $N o D=2$ \\
\hline Ort. & 1.4167 & 1.7854 & 1.6415 & 2.0413 \\
\hline$S t d$ & 0.0195 & 0.0413 & 0.0353 & 0.0299 \\
\hline \multirow{3}{*}{ Sen. } & \multicolumn{4}{|c|}{$P S=50$} \\
\hline & \multicolumn{2}{|c|}{ NoR $=1$} & \multicolumn{2}{|c|}{ NoR $=2$} \\
\hline & $N o D=1$ & $N o D=2$ & $N o D=1$ & $N o D=2$ \\
\hline Ort. & 1.1969 & 1.4352 & 1.3138 & 1.5240 \\
\hline Std. & 0.0265 & 0.0161 & 0.0175 & 0.0074 \\
\hline \multirow{3}{*}{ Sen. } & \multicolumn{4}{|c|}{$P S=100$} \\
\hline & \multicolumn{2}{|c|}{$N o R=1$} & \multicolumn{2}{|c|}{$N o R=2$} \\
\hline & $N o D=1$ & NoD $=2$ & $N o D=1$ & $N o D=2$ \\
\hline Ort. & 1.0426 & 1.1503 & 1.0774 & 1.2159 \\
\hline Std. & 0.0198 & 0.0065 & 0.0228 & 0.0208 \\
\hline
\end{tabular}

IP algoritması ile birden fazla bilişsel radyonun bulunduğu kanal atama problemi çözülürken IPA'nın işlem adımları amaç doğrultusunda modifiye edilmiştir. Birincil kullanıcılar ve bilişsel radyolar arasındaki ya da bilişsel radyo ve diğer bilişsel radyolar arasındaki çakışmaları engellemek için algoritmanın çalışma prensiplerine uygun bir düzenleme fonksiyonu geliştirilmiştir. Algoritma üzerinde yapılan modifikasyonlar ve düzenleme fonksiyonu diğer meta-sezgisel algoritmalar üzerinde performans azalması yapabileceğinden adil olmayan bir karşılaştırma yapılmasından kaçınılmıştır. IPA ile elde edilen sonuçlar Kaba Kuvvet (BF) algoritması ile dört adet bilişsel radyo için karşılaştırılmıştır. BF için 15000, 150000, 1500000 değerlendirme sayısı ile elde edilen sonuçlar, IPA'da en iyi sonucu veren popülasyon sayıs1 $30, \mathrm{NoD}$ ve NoR parametrelerinin 1 olduğu senaryo seçilmiştir. Tablo 4'te görüldüğü üzere IP algortimasında 15000 değerlendirme sayısında elde edilen sonuç, BF ile daha fazla değerlendirme sayısıyla elde edilen sonuçlardan daha iyidir.

Tablo 4. IPA ve BF ile bulunan sonuçların klyaslanması

\begin{tabular}{|c|c|c|c|c|}
\hline \multirow{2}{*}{ Sen. } & \multirow{2}{*}{$\boldsymbol{I P A}$} & \multicolumn{3}{|c|}{$\boldsymbol{B F}$} \\
\cline { 3 - 5 } & & $\boldsymbol{D S = 1 . 5 e + 0 4}$ & $\boldsymbol{D S}=\mathbf{1 . 5} \boldsymbol{e}+\mathbf{0 5}$ & $\boldsymbol{D S}=\mathbf{1 . 5 e + 0 6}$ \\
\hline Ort. & 36.4664 & $43.0000 \mathrm{e}+00$ & $41.0000 \mathrm{e}+00$ & $41.0000 \mathrm{e}+00$ \\
\hline Std. & 1.6069 & $0.0000 \mathrm{e}+00$ & $0.0000 \mathrm{e}+00$ & $0.0000 \mathrm{e}+00$ \\
\hline
\end{tabular}

\section{Sonuç}

Çalışmada bilişsel radyo ağı içerisinde birden fazla lisanssız kullanıcının bulunduğu kanal atama probleminin çözümü için İmmün plazma algoritması amaca uygun bir şekilde modifiye edilmiştir. Lisanslı kullanıcılar veya bilişsel radyo kullanıcıları arasındaki olası frekans çakışmalarını engellemek için bir düzenleme fonksiyonu geliştirilmiştir. Birden fazla lisanssız kullanıcının bulunduğu bir bilişsel ağ modeli için IP algoritmasının modellenerek kullanılabileceği gösterilmiştir. Farklı popülasyon büyüklükleriyle dönor ve alıcı birey sayılarına göre değişen skorlar incelenmiştir. IP algoritmasıyla daha az işlem sayısıyla BF'ye göre daha iyi sonuçlar elde edilmiştir.

\section{Kaynakça}

Mitola, J., and Maguire, G. Q., "Cognitive Radio: Making Software Radios More Personal", IEEE Personal Communications, vol. 6, no. 4, pp. 13-18, 1999.

Haykin, S., "Cognitive Radio: Brain-empowered Wireless Communications", IEEE Journal on Selected Areas in Communications, vol. 23, no. 2, pp. 201-220, 2005.

Akyildiz, I.F., Lee, W.Y., Vuran, M.C., and Mohanty, S., "Next Generation/Dynamic Spectrum Access/Cognitive Radio Wireless Networks: A Survey", Computer Networks, vol. 50, no. 13, pp. 2127-2159, 2006.

Lazos, L., Liu, S., and Krunz, M., "Spectrum Opportunity-based Control Channel Assignment in Cognitive Radio Networks", in 6th Annual IEEE Communications Society Conference on Sensor, Mesh and Adhoc Communications and Networks, pp. 1-9, 2009.

Salameh, H. B. (2010, December). Rate-maximization channel assignment scheme for cognitive radio networks. In 2010 IEEE Global Telecommunications Conference GLOBECOM 2010 (pp. 1-5). IEEE.

Bayhan, S., and Alagoz, F., "Scheduling in Centralized Cognitive Radio Networks for Energy Efficiency", IEEE Transactions on Vehicular Technology, vol. 62, no. 2, pp. 
582-595, 2012.

Ahmed, E., Gani, A., Abolfazli, S., Yao, L. J., and Khan, S. U., "Channel Assignment Algorithms in Cognitive Radio Networks: Taxonomy, Open Issues, and Challenges", IEEE Communications Surveys \& Tutorials, vol. 18, no. 1, pp. 795-823, 2014.

Tang, F., \& Li, J. (2016). Joint rate adaptation, channel assignment and routing to maximize social welfare in multihop cognitive radio networks. IEEE Transactions on Wireless Communications, 16(4), 2097-2110.

Gupta, N., and Dhurandher, S. K., "Cross-layer Perspective for Channel Assignment in Cognitive Radio Networks: A Survey", International Journal of Communication Systems, vol. 33, no. 5, 2020.

Akan, O.B., Karli, O.B. and Ergul, O., 2009. Cognitive Radio Sensor Networks.Netwrk. Mag. of Global Internetwkg., 23(4):34-40.

Dokuz, Y., "Bilişsel Radyo Uygulamaları için En Uygun Frekansın Zamansal ve Mekansal Olarak Yapay Arı Koloni Algoritmas1 ile Belirlenmesi", Erciyes Üniversitesi Fen Bilimleri Enstitüsü, pp. 1-82, 2014.

Qin, Y., Zhong, X., Yang, Y., Li, L., and Ye, Y., "Combined Channel Assignment and Network Coded Opportunistic Routing in Cognitive Radio Networks", Computers \& Electrical Engineering, vol. 52, pp. 293-306, 2016.

Wei, Z. H., and Hu, B. J., "A Fair Multi-channel Assignment Algorithm with Practical Implementation in Distributed Cognitive Radio Networks", IEEE Access, vol. 6, pp. 14255-14267, 2018.

Demirci, S., and Gözüpek, D., "Switching Cost-Aware Joint Frequency Assignment and Scheduling for Industrial Cognitive Radio Networks", IEEE Transactions on Industrial Informatics, vol. 16, no. 7, pp. 4365-4377, 2019.

Salameh, H. B., Shraideh, S., and Alshamali, A., "Joint ChannelAssignment and Adaptive Mode Selection in MIMO-based Cognitive Radio Networks", Arabian Journal for Science and Engineering, vol. 45, no. 212, pp. 1023310244, 2020.

Raju, V. A., Srilatha, P., Anumandla, K. K., Patnaik, S., and Prabu, A. V., "Grasshopper Algorithm based Channel Assignment for Cognitive Radio Networks", Materials Today: Proceedings, pp. 1-6, 2020.

Musa, A., Bany Salameh, H., Abu Sannad, N., Halloush, R., and Darabkh, K., "Spectrum Management with Simultaneous Power-controlled Assignment Decisions in Cognitive Radio Networks", Concurrency and Computation: Practice and Experience, vol. 32, no. 21, 2020.

Latif, S., Akraam, S., Malik, A. J., Abbasi, A. A., Habib, M., and Lim, S., "Improved Channel Allocation Scheme for Cognitive Radio Networks", Intelligent Automation and Soft Computing, vol. 27, no. 1, pp. 103-114, 2021.

Sanka, S. N., Yarram, T. R., Yenumala, K. C., Anumandla, K. K., and Dabbakuti, J. K., "Dragonfly Algorithm based Spectrum Assignment for Cognitive Radio Networks", Materials Today: Proceedings, pp. 1-4, 2021.

Tlouyamma, J., and Velempini, M., "Channel Selection Algorithm Optimized for Improved Performance in Cognitive Radio Networks", Wireless Personal Communications, pp. 1-18, 2021.

Aslan, S., and Demirci, S., "Immune Plasma Algorithm: A Novel Meta-Heuristic for Optimization Problems", IEEE Access, vol. 8, pp. 220227- 220245, 2020.
Devi, M., Sarma, N., \& Deka, SK (2021). Bilişsel Radyo Ağlarında Çok Kazanan Spektrum Tahsisi: Sıralı Teklif Verme ile Tek Taraflı Açık Artırma Teorik Modelleme Yaklaşımı. Elektronik, 10 (5), 602.

Yilmazel, R., \& Inanç, N. (2021). A Novel Approach for Channel Allocation In OFDM Based Cognitive Radio Technology. Wireless Personal Communications, 1-15.

Goyal, K. ve Patra, M. (2021). Bilişsel-Radyo Destekli Araçların İnternetinde Dağıtılmış Kanal Atama. Gelen Intelligent Systems (s. 217-227). Springer, Singapur.

Agarwal, S., Vijay, S., \& Bagwari, A. (2021). An Enhanced Spectrum Allocation Algorithm for Secondary Users in Cognitive Radio Networks. 